\title{
An association study between the dymeclin gene and schizophrenia in the Japanese population
}

\author{
Saori Yazaki ${ }^{1}$, Minori Koga ${ }^{1,2}$, Hiroki Ishiguro ${ }^{1,2}$, Toshiya Inada ${ }^{3}$, Hiroshi Ujike ${ }^{4}$, Masanari Itokawa ${ }^{5}$, \\ Takeshi Otowa $^{6}$, Yuichiro Watanabe ${ }^{7}$, Toshiyuki Someya ${ }^{7}$, Nakao Iwata ${ }^{8}$, Hiroshi Kunugi ${ }^{9}$, Norio Ozaki ${ }^{10}$ and \\ Tadao Arinami ${ }^{1,2}$
}

\begin{abstract}
Many gene variants are involved in the susceptibility to schizophrenia and some of them are expected to be associated with other human characters. Recently reported meta-analysis of genetic associations revealed nucleotide variants in synaptic vesicular transport/Golgi apparatus genes with schizophrenia. In this study, we selected the dymeclin gene (DYM) as a candidate gene for schizophrenia. The DYM gene encodes dymeclin that has been identified to be associated with the Golgi apparatus and with transitional vesicles of the reticulum-Golgi interface. A three-step case-control study of total of 2105 Japanese cases of schizophrenia and 2087 Japanese control subjects was carried out for tag single-nucleotide polymorphisms (SNPs) in the DYM gene and an association between an SNP, rs833497, and schizophrenia was identified (allelic $P=2 \times 10^{-5}$, in the total sample). $D Y M$ is the causal gene for Dyggve-Melchior-Clausen syndrome and this study shows the second neuropsychiatric disorder in which the DYM gene is involved. The present data support the involvement of Golgi function and vesicular transport in the presynapse in schizophrenia.
\end{abstract}

Journal of Human Genetics (2010) 55, 631-634; doi:10.1038/jhg.2010.72; published online 17 June 2010

Keywords: association; Dyggve-Melchior-Clausen syndrome; Golgi; postmortem study; SNP

\section{INTRODUCTION}

Schizophrenia is a chronic, severe and disabling brain disorder that affects approximately $1 \%$ of the world's population. Family and twin studies indicate a strong genetic factor and recent genome-wide association studies provided molecular genetic evidence for a substantial polygenic component to the risk of schizophrenia involving many common alleles of very small effect. ${ }^{1,2}$ Some of the genetic factors influencing susceptibility to schizophrenia may also have roles in other phenotypes.

In a recent study, ${ }^{3}$ in which mRNA abundance was determined by sequencing mRNA in postmortem cerebellum, gene ontology annotation of genes with significantly altered expression revealed overrepresentation of membrane-associated genes, genes involved in zinc binding or transport, regulation of transcription, Golgi apparatus and vesicle-mediated transport. The authors mentioned that most striking were 23 genes involved in presynaptic vesicular transport/ Golgi apparatus or postsynaptic neurotransmission. Meta-analysis of genetic associations revealed nucleotide variants in synaptic vesicular transport/Golgi apparatus genes with schizophrenia (DTNBP1, DISC1, DAOA, NRG1). ${ }^{4}$ Reelin accumulated in the Golgi and endoplasmic reticulum in some cell bodies of GABAergic neurons in the cortex and hippocampus, ${ }^{5}$ and genetic associations of the reelin gene polymorphism and schizophrenia were reported. ${ }^{6,7}$

Recently, dymeclin has been identified to be associated with the Golgi apparatus and with transitional vesicles of the reticulum-Golgi interface and it seems to be involved in cellular vesicle trafficking. ${ }^{8,9}$ The DYM gene, located in chromosome 18q21.1 and encoding dymeclin, is a causative gene for Dyggve-Melchior-Clausen syndrome, which shows dwarfism and mental retardation. Furthermore, previous studies have identified a putative gene locus for both schizophrenia and bipolar disorder in the $18 \mathrm{q} 21$ region. ${ }^{10,11}$ The aim of this study was to evaluate genetic associations of polymorphism(s) in the DYM gene with schizophrenia.

\section{MATERIALS AND METHODS}

All subjects were unrelated and of Japanese descent and were recruited from the main island of Japan. The first sample set was 576 patients with schizophrenia (mean age \pm s.d., $51.6 \pm 14.8$ years; 322 men and 254 women) and 576 control subjects (mean age \pm s.d., $46.8 \pm 12.5$ years; 268 men and 308 women). The second sample set was 1344 patients with schizophrenia (mean age \pm s.d.,

${ }^{1}$ Department of Medical Genetics, Graduate School of Comprehensive Human Sciences, University of Tsukuba, Tsukuba, Japan; ${ }^{2}$ CREST, Japan Science and Technology Agency, Kawaguchi-shi, Japan; ${ }^{3}$ Institute of Neuropsychiatry, Seiwa Hospital, Tokyo, Japan; ${ }^{4}$ Department of Neuropsychiatry, Okayama University, Graduate School of Medicine, Dentistry \& Pharmaceutical Sciences, Okayama, Japan; ${ }^{5}$ Department of Schizophrenia Research, Tokyo Institute of Psychiatry, Tokyo, Japan; ${ }^{6}$ Department of Neuropsychiatry, Graduate School of Medicine, University of Tokyo, Tokyo, Japan; ${ }^{7}$ Department of Psychiatry, Niigata University Graduate School of Medical and Dental Sciences, Niigata, Japan; ${ }^{8}$ Department of Psychiatry, Fujita Health University School of Medicine, Toyoake, Japan; ${ }^{9}$ Department of Mental Disorder Research, National Institute of Neuroscience, National Center of Neurology and Psychiatry, Tokyo, Japan and ${ }^{10}$ Department of Psychiatry, School of Medicine, Nagoya University, Nagoya, Japan

Correspondence: Professor T Arinami, Department of Medical Genetics, Graduate School of Comprehensive Human Sciences, University of Tsukuba, 1-1-1 Tennoudai, Tsukuba, Ibaraki 305-8575, Japan.

E-mail: tarinami@md.tsukuba.ac.jp

Received 14 April 2010; revised 21 May 2010; accepted 24 May 2010; published online 17 June 2010 
$46.7 \pm 14.4$ years; 733 men and 611 women) and 1344 control subjects (mean age \pm s.d., $47.8 \pm 13.8$ years; 783 men and 561 women). The third sample set was 212 patients with schizophrenia (mean age \pm s.d., $37.3 \pm 11.4$ years; 107 men and 105 women) and 189 control subjects (mean age \pm s.d., $37.6 \pm 11.5$ years; 92 men and 97 women). Consensual diagnosis of schizophrenia was made according to the Diagnostic and Statistical Manual of Mental Disorders, Fourth Edition (American Psychiatric Association, 1994). Control subjects had no history of mental illness and second-degree relatives were free of psychosis in a brief psychiatric interview. This study was approved by the ethics committees of the University of Tsukuba, Niigata University, Fujita Health University, Nagoya University, Okayama University and Seiwa Hospital; and all participants provided written informed consent.

DNA was extracted from blood samples. We genotyped a total of 14 singlenucleotide polymorphisms (SNPs), rs833523, rs357894, rs2044550, rs833497, rs8089472, rs12606288, rs1297381, rs1943000, rs4630621, rs4491603, rs16950465, rs11082743, rs3809924 and rs12606865. The tag SNPs in the gene were selected using the Haploview program (http://www.broad.mit.edu/mpg/ haploview/) with the condition of an $r^{2}$ threshold of 0.8 and a minor allele frequency of 0.1. SNPs were genotyped by TaqMan genotyping (Applied Biosystems, Foster City, CA, USA). Although the DYM gene spans $417 \mathrm{~kb}$, the gene coverage was reached with these 14 SNPs because the gene resided in a large linkage disequilibrium block. Predesigned TaqMan SNP genotyping assays were selected from the Applied Biosystems database (http://www.appliedbio systems.com). The TaqMan reaction was performed in a final volume of $3 \mu \mathrm{l}$ consisting of $2.5 \mathrm{ng}$ genomic DNA and Universal Master Mix (Eurogentec, Seraing, Belgium), and genotying was performed with an ABI PRISM 7900HT Sequence Detection System (Applied Biosystems).

In this study, we carried out a three-step case-control association procedure; that is, screening and two independent confirmation studies. SNPs with allelic $P$-values for associations of $<0.05$ were examined in the second case-control sets, and SNPs with allelic $P$-values $<0.05$ in the second set were examined in the third case-control sets. Significant association was defined when SNPs survived these three-step procedures.

The Hardy-Weinberg equilibrium and an association between SNP and schizophrenia were determined with the Haploview software program (http:// www.broad.mit.edu/mpg/haploview/). Genotype-based association was tested with the Cochran-Armitage test for trend.

\section{RESULTS}

In the first screening, we genotyped 14 tag SNPs in 1152 individuals (Figure 1). Genotypic distributions of these SNPs are shown in
Table 1. Distributions of all SNPs did not differ significantly from the Hardy-Weinberg equilibrium. Nominally significant association was observed in 4 out of 14 SNPs; rs833523 $(P=0.005)$, rs357894 $(P=0.004), \operatorname{rs} 833497(P=0.007)$ and $\operatorname{rs} 3809924(P=0.005)$.

In the second sample set, these 4 SNPs were genotyped in 2688 individuals. One SNP (rs833497) was significantly associated with schizophrenia ( $P=0.006$, one sided, Table 2$)$. In the third sample set, rs833497 was again genotyped in 404 individuals and the association was confirmed ( $P=0.006$, one-sided, Table 3$)$. In the combined total samples, the allelic $P$-value for association with schizophrenia was $2 \times 10^{-5}$ (Table 3 ). The association was observed in both male and female subjects (data not shown).

\section{DISCUSSION}

To our knowledge, this is the first report on the association between DYM gene variants and schizophrenia. Four SNPs among 14 tag SNPs we examined showed a trend for association in the screening samples (permutation allelic $P$-values from 0.05 to 0.06 ). Among the four SNPs, an association of SNP 4 (rs833894) with schizophrenia was confirmed in the second and third case-control samples. Thus, the SNP rs833497 was found to be associated with schizophrenia in this study.

The SNP is not likely to exert an important effect on dymeclin function, because rs833497 is located in the last intron of the DYM gene, and therefore, it is assumed that the SNP is in linkage disequilibrium with causal $\mathrm{SNP}(\mathrm{s})$ for the association. However, rs833497 was in no complete linkage disequilibrium with other SNPs in this study and in the International HapMap database (http://hapmap.ncbi.nlm.nih.gov/). Therefore, we could not predict where the supposed causal variation(s) is. In addition, because no variant in the exons has been identified by the JSNP project (http:// snp.ims.u-tokyo.ac.jp/search_Gene.html), we did not perform resequencing of the DNA of our subjects.

The DYM gene is located at chromosome 18q21. Previous linkage and cytogenetic studies reported the 18q21 region for both schizophrenia and bipolar disorders. ${ }^{10,11}$ However, genome-wide association studies in other populations have not reported a significant association between variants in the DYM gene and schizophrenia or bipolar disorders. In the Wellcome Trust Case Control Consortium

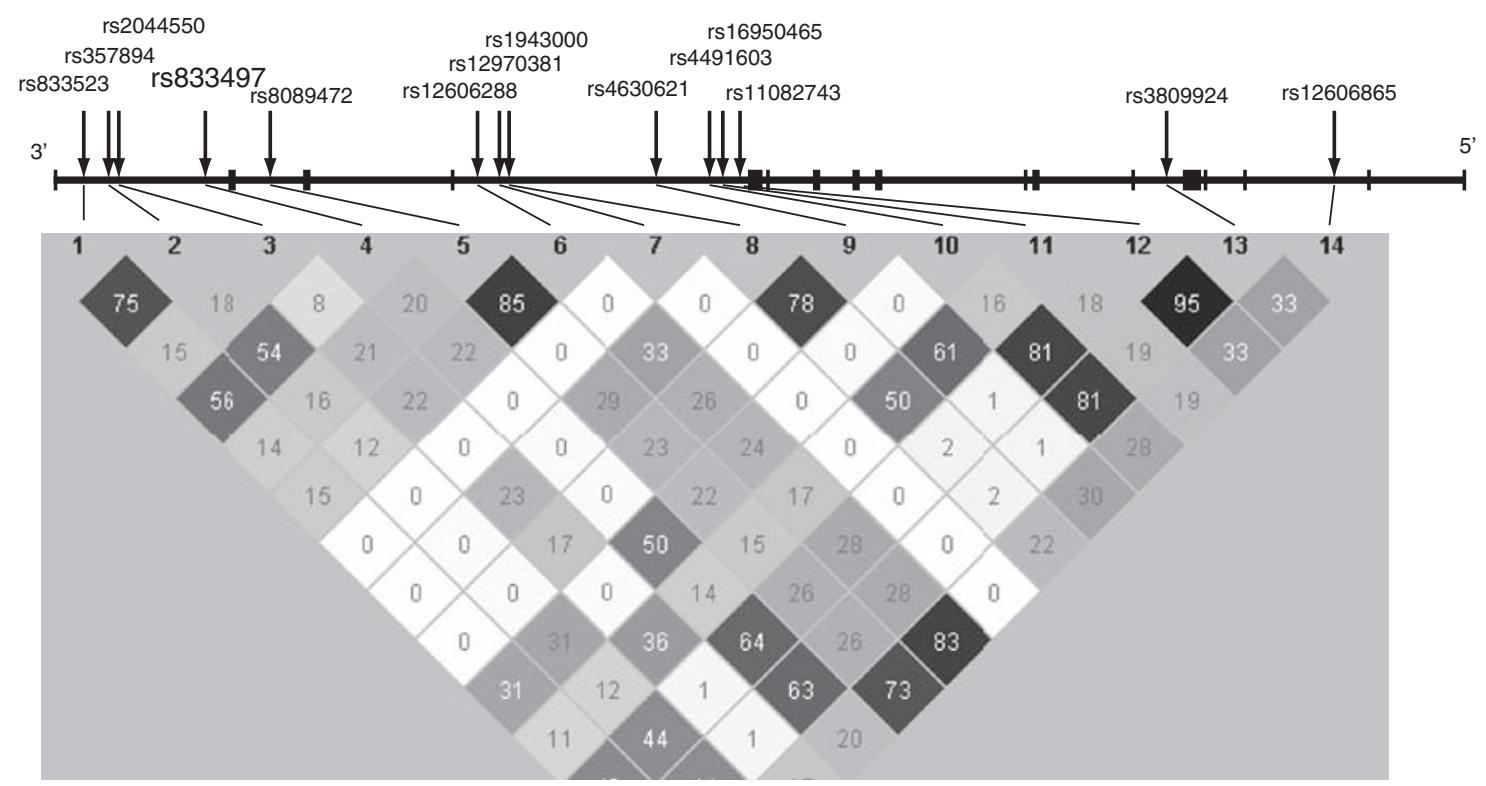

Figure 1 Positions and pairwise linkage disequilibrium (LD) of 14 tag SNPs genotyped in the DYM gene. 
Table 1 Screening for associations between tag SNPs in the DYM gene and schizophrenia

\begin{tabular}{|c|c|c|c|c|c|c|c|c|c|}
\hline \multirow{2}{*}{ Polymorphism (NCBI ID) } & \multirow[t]{2}{*}{ Subjects } & \multirow[t]{2}{*}{$n$} & \multicolumn{3}{|c|}{ Genotype count (frequency) } & \multirow[t]{2}{*}{$\mathrm{Pa}$} & \multicolumn{2}{|c|}{ Allele count (frequency) } & \multirow{2}{*}{$P^{b}\left(P^{c}\right)$} \\
\hline & & & $A A$ & $\mathrm{GA}$ & GG & & $A$ & $\mathrm{G}$ & \\
\hline \multirow[t]{3}{*}{ SNP 1 (rs833523) intron 16} & Affected & 571 & $47(0.08)$ & $227(0.40)$ & $297(0.52)$ & & $321(0.28)$ & $821(0.72)$ & $0.005(0.05)$ \\
\hline & Controls & 567 & $35(0.06)$ & $191(0.34)$ & $341(0.60)$ & 0.006 & $261(0.23)$ & $873(0.77)$ & \\
\hline & & & $\mathrm{CC}$ & CT & TT & & C & $\mathrm{T}$ & \\
\hline \multirow[t]{3}{*}{ SNP 2 (rs357894) intron 16} & Affected & 572 & $274(0.48)$ & $241(0.42)$ & $57(0.10)$ & & 789 (0.69) & $355(0.31)$ & $0.004(0.05)$ \\
\hline & Controls & 569 & $315(0.55)$ & $216(0.38)$ & $38(0.07)$ & 0.02 & $846(0.74)$ & $292(0.26)$ & \\
\hline & & & $\mathrm{CC}$ & CT & TT & & C & $\mathrm{T}$ & \\
\hline \multirow[t]{3}{*}{ SNP 3 (rs2044550) intron 16} & Affected & 570 & $271(0.48)$ & $237(0.42)$ & $62(0.11)$ & & $779(0.68)$ & $361(0.32)$ & $0.10(0.55)$ \\
\hline & Controls & 567 & $255(0.45)$ & $228(0.40)$ & $84(0.15)$ & 0.14 & $738(0.65)$ & $396(0.35)$ & \\
\hline & & & $\mathrm{CC}$ & $\mathrm{TC}$ & $\mathrm{TT}$ & & $\mathrm{C}$ & $\mathrm{T}$ & \\
\hline \multirow[t]{3}{*}{ SNP 4 (rs833497) intron 16} & Affected & 571 & $72(0.13)$ & $257(0.45)$ & $242(0.42)$ & & $401(0.35)$ & $741(0.65)$ & $0.007(0.06)$ \\
\hline & Controls & 570 & $55(0.10)$ & $230(0.40)$ & $285(0.50)$ & 0.03 & $340(0.30)$ & $800(0.70)$ & \\
\hline & & & GG & GT & TT & & $G$ & $\mathrm{~T}$ & \\
\hline \multirow[t]{3}{*}{ SNP 5 (rs8089472) intron 15} & Affected & 563 & $257(0.46)$ & $246(0.44)$ & $60(0.11)$ & & $760(0.67)$ & $366(0.33)$ & $0.271(0.87)$ \\
\hline & Controls & 543 & 237(0.44) & $235(0.43)$ & $71(0.13)$ & 0.44 & $709(0.65)$ & $377(0.35)$ & \\
\hline & & & $\mathrm{TT}$ & $\mathrm{TC}$ & $\mathrm{CC}$ & & $\mathrm{T}$ & $\mathrm{C}$ & \\
\hline \multirow[t]{3}{*}{ SNP 6 (rs12606288) intron 14} & Affected & 559 & $61(0.11)$ & $251(0.45)$ & $247(0.44)$ & & $373(0.33)$ & $745(0.67)$ & 0.20 \\
\hline & Controls & 556 & $84(0.15)$ & $232(0.43)$ & $240(0.43)$ & 0.11 & $400(0.36)$ & $712(0.64)$ & 0.76 \\
\hline & & & TT & $\mathrm{TG}$ & GG & & $\mathrm{T}$ & $G$ & \\
\hline \multirow[t]{3}{*}{ SNP 7 (rs12970381) intron 13} & Affected & 567 & $38(0.07)$ & $233(0.41)$ & $296(0.52)$ & & $309(0.27)$ & $825(0.73)$ & 0.23 \\
\hline & Controls & 567 & $41(0.07)$ & $202(0.57)$ & $324(0.57)$ & 0.17 & $284(0.25)$ & $850(0.75)$ & 0.75 \\
\hline & & & GG & GA & $\mathrm{AA}$ & & G & A & \\
\hline \multirow[t]{3}{*}{ SNP 8 (rs1943000) intron 13} & Affected & 572 & $89(0.16)$ & $276(0.48)$ & $207(0.36)$ & & $454(0.40)$ & $690(0.60)$ & 0.98 \\
\hline & Controls & 570 & $98(0.17)$ & $257(0.38)$ & $215(0.38)$ & 0.53 & $453(0.40)$ & $687(0.60)$ & 1.00 \\
\hline & & & TT & TC & $\mathrm{CC}$ & & $\mathrm{T}$ & C & \\
\hline \multirow[t]{3}{*}{ SNP 9 (rs4630621) intron 13} & Affected & 573 & $67(0.12)$ & $266(0.46)$ & $240(0.42)$ & & $400(0.35)$ & $746(0.65)$ & $0.62(0.99)$ \\
\hline & Controls & 564 & $82(0.15)$ & $241(0.43)$ & $241(0.43)$ & 0.26 & $405(0.36)$ & $723(0.64)$ & \\
\hline & & & GG & GC & $\mathrm{CC}$ & & $\mathrm{G}$ & $\mathrm{C}$ & \\
\hline \multirow[t]{3}{*}{ SNP 10 (rs4491603) intron 13} & Affected & 569 & $62(0.11)$ & $268(0.47)$ & $239(0.42)$ & & $392(0.34)$ & $746(0.66)$ & $0.12(0.68)$ \\
\hline & Controls & 570 & $60(0.11)$ & $238(0.48)$ & $272(0.48)$ & 0.14 & $358(0.31)$ & 782 (0.69) & \\
\hline & & & $\mathrm{CC}$ & $\mathrm{CT}$ & TT & & $\mathrm{C}$ & $\mathrm{T}$ & \\
\hline \multirow[t]{3}{*}{ SNP 11 (rs16950465) intron 13} & Affected & 572 & $331(0.58)$ & $210(0.37)$ & $31(0.05)$ & & $872(0.76)$ & $272(0.24)$ & $0.08(0.44)$ \\
\hline & Controls & 569 & $305(0.54)$ & $221(0.08)$ & $43(0.08)$ & 0.19 & $831(0.73)$ & $307(0.27)$ & \\
\hline & & & $\mathrm{CC}$ & CT & TT & & C & $\mathrm{T}$ & \\
\hline \multirow[t]{3}{*}{ SNP 12 (rs11082743) intron 13} & Affected & 570 & $208(0.36)$ & $280(0.49)$ & $82(0.14)$ & & $696(0.61)$ & $444(0.39)$ & $0.01(0.11)$ \\
\hline & Controls & 568 & $250(0.44)$ & $251(0.12)$ & $67(0.12)$ & 0.03 & $751(0.66)$ & $385(0.34)$ & \\
\hline & & & AA & $A G$ & GG & & A & G & \\
\hline \multirow[t]{3}{*}{ SNP 13 (rs3809924) intron 5} & Affected & 570 & $206(0.36)$ & $282(0.49)$ & $82(0.14)$ & & $694(0.61)$ & $446(0.39)$ & $0.005(0.06)$ \\
\hline & Controls & 571 & $257(0.45)$ & $246(0.12)$ & $68(0.12)$ & 0.01 & $760(0.67)$ & $382(0.33)$ & \\
\hline & & & AA & $A G$ & GG & & A & G & \\
\hline \multirow[t]{2}{*}{ SNP 14 (rs12606865) intron 2} & Affected & 572 & $221(0.39)$ & $277(0.48)$ & $74(0.13)$ & & $719(0.63)$ & $425(0.37)$ & $0.38(0.95)$ \\
\hline & Controls & 569 & $229(0.40)$ & $237(0.18)$ & $103(0.18)$ & 0.018 & $695(0.61)$ & $443(0.39)$ & \\
\hline
\end{tabular}

The Cochran-Armitage test.

bFisher's exact test (two-sided). $P$ values in bold letters indicate nominal $P<0.05$.

cPermutation test (10000 permutations). $P$ values in bold letters indicate permutation $P<0.1$.

genome-wide association studies data, ${ }^{12}$ the $\mathrm{T}$ allele of $\mathrm{rs} 357897$ located near rs833497 was more frequent in 2000 bipolar cases than in 3000 controls from the United Kingdom $(P=0.009)$. The HapMap data of the Japanese population shows a moderate linkage disequilibrium between the $\mathrm{T}$ allele of $\mathrm{rs} 357897$ and the risk $\mathrm{C}$ allele of rs833497 in this study $\left(r^{2}=0.25, D^{\prime}=1\right)$. A significant different expression profile of the DYM gene has not been found in the postmortem brain samples between patients with schizophrenia and controls in the Stanley Medical Research Institute Online Genomics Database (https://www.stanleygenomics.org/). Thus, no evidence supporting involvement of the DYM gene in schizophrenia has been found in other populations.

The DYM gene encodes a protein, dymeclin, which is necessary for normal skeletal development and brain function. Defects in DYM gene are the cause of Dyggve-Melchior-Clausen (DMC) syndrome (MIM 223800), a rare autosomal recessive disorder characterized by short limbs, a short trunk, dwarfism, microcephaly and psychomotor retardation. ${ }^{13-15}$ DMC syndrome is progressive. Smith-McCort dysplasia (MIM 607326), a rare autosomal recessive osteochondrodysplasia characterized by short limbs and a short trunk with a barrel-shaped chest but without mental retardation, is hypothesized to be allelic with DMC syndrome. ${ }^{14,16}$ Most $^{3}$ mutations identified in DMC syndrome predict a loss of function, whereas those identified in Smith-McCort dysplasia are mainly missense mutations. ${ }^{13-15,17}$ The missense mutation (N469Y) causing DMC syndrome resulted in a mislocation and subsequent protein degradation, whereas the E87K Smith-McCort mutation does not affect the stability and the location of the protein. ${ }^{8}$ Dymeclin could not be ascribed to any family of proteins. DYM is 
Table 2 Replication analyses of SNPs in the DYM gene potentially associated with schizophrenia

\begin{tabular}{|c|c|c|c|c|c|c|c|c|c|}
\hline Polymorphism (NCBI ID) & Subjects & $\mathrm{n}$ & \multicolumn{3}{|c|}{ Genotype count (frequency) } & $\mathrm{p}^{a}$ & \multicolumn{2}{|c|}{ Allele count (frequency) } & $\mathrm{P}^{\mathrm{b}}\left(\mathrm{P}^{\mathrm{c}}\right)$ \\
\hline \multirow[t]{2}{*}{ SNP 1 (rs833523) } & Affected & 1332 & $79(0.06)$ & $512(0.38)$ & $741(0.56)$ & & $670(0.25)$ & $1994(0.75)$ & \\
\hline & & & $\mathrm{CC}$ & $\mathrm{CT}$ & $\mathrm{TT}$ & & $\mathrm{C}$ & $T$ & \\
\hline \multirow[t]{2}{*}{ SNP 2 (rs357894) } & Affected & 1325 & $702(0.53)$ & $529(0.40)$ & $94(0.07)$ & & $1933(0.73)$ & $717(0.27)$ & \\
\hline & Controls & 1323 & $689(0.52)$ & $530(0.40)$ & $104(0.08)$ & 0.73 & $1908(0.72)$ & $738(0.28)$ & 1.00 \\
\hline & Controls & 1328 & $117(0.09)$ & $548(0.41)$ & $663(0.50)$ & 0.01 & $782(0.29)$ & $1874(0.71)$ & \\
\hline & & & $\mathrm{AA}$ & $A G$ & GG & & $A$ & G & \\
\hline \multirow[t]{2}{*}{ SNP 13 (rs3809924) } & Affected & 1326 & $539(0.41)$ & $602(0.45)$ & $185(0.14)$ & & $1680(0.63)$ & $972(0.37)$ & \\
\hline & Controls & 1309 & $534(0.41)$ & $594(0.45)$ & $181(0.14)$ & 0.99 & $1662(0.63)$ & $956(0.37)$ & 0.47 \\
\hline
\end{tabular}

aThe Cochran-Armitage test.

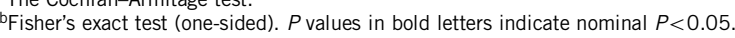

'Permutation test (10000 permutations). $P$ values in bold letters indicate permutation $P<0.05$.

Table 3 The third replication analysis and combined association data of rs 833497

\begin{tabular}{|c|c|c|c|c|c|c|c|c|c|c|}
\hline \multirow[t]{2}{*}{ Population } & \multirow[t]{2}{*}{ Subjects } & \multirow[t]{2}{*}{$\mathrm{n}$} & \multicolumn{3}{|c|}{ Genotype count (frequency) } & \multirow[t]{2}{*}{$\mathrm{P}^{\mathrm{a}}$} & \multicolumn{2}{|c|}{ Allele count (frequency) } & \multirow[t]{2}{*}{$\mathrm{P}^{\mathrm{b}}$} & \multirow[t]{2}{*}{ Odds ratio $(95 \% \mathrm{Cl})$} \\
\hline & & & CC & TC & $\mathrm{TT}$ & & C & T & & \\
\hline \multirow[t]{2}{*}{ Third } & Affected & 212 & $36(0.17)$ & $90(0.42)$ & $86(0.41)$ & & $162(0.38)$ & $262(0.62)$ & & \\
\hline & & & $\mathrm{CC}$ & $\mathrm{TC}$ & TT & & C & $\mathrm{T}$ & & \\
\hline \multirow[t]{2}{*}{ Combined total } & Affected & 2105 & $250(0.12)$ & $927(0.44)$ & $928(0.44)$ & & $1427(0.34)$ & $2783(0.66)$ & & $1.16(1.06-1.27)$ \\
\hline & Controls & 2087 & $189(0.09)$ & $856(0.41)$ & $1042(0.50)$ & 0.00002 & $1234(0.30)$ & $2940(0.70)$ & 0.00002 & \\
\hline
\end{tabular}

aThe Cochran-Armitage tests.

bFisher's exact test (one-sided for the third population and two-sided for the combined total).

$P$ values in bold letters indicated $P<0.05$.

widely expressed in human embryos, especially in the cortex, the hippocampus and the cerebellum. Because dymeclin associates with the Golgi apparatus and with transitional vesicles of the reticulumGolgi interface, it seems to be involved in cellular vesicle trafficking. ${ }^{8,9}$ Differences in the expression of genes involved in Golgi function and vesicular transport in the presynapse have been reported in the postmortem cerebellar cortex of schizophrenia patients. ${ }^{3}$

In conclusion, this case-control study suggests involvement of dymeclin in the susceptibility to schizophrenia.

\section{ACKNOWLEDGEMENTS}

This article was supported by Kakenhi 20023006 and 20390098 and a grant from Mitsubishi Pharma Research Foundation.

1 Purcell, S. M., Wray, N. R., Stone, J. L., Visscher, P. M., O'Donovan, M. C., Sullivan, P. F. et al. Common polygenic variation contributes to risk of schizophrenia and bipolar disorder. Nature 460, 748-752 (2009).

2 Owen, M. J., Williams, N. M. \& O'Donovan, M. C. The molecular genetics of schizophrenia: new findings promise new insights. Mol. Psychiatry 9, 14-27 (2004).

3 Mudge, J., Miller, N. A., Khrebtukova, I., Lindquist, I. E., May, G. D., Huntley, J. J. et al. Genomic convergence analysis of schizophrenia: mRNA sequencing reveals altered synaptic vesicular transport in post-mortem cerebellum. PLoS One 3, e3625 (2008).

4 Allen, N. C., Bagade, S., McQueen, M. B., Ioannidis, J. P., Kavvoura, F. K., Khoury, M. J. et al. Systematic meta-analyses and field synopsis of genetic association studies in schizophrenia: the SzGene database. Nat. Genet. 40, 827-834 (2008).

5 Pappas, G. D., Kriho, V. \& Pesold, C. Reelin in the extracellular matrix and dendritic spines of the cortex and hippocampus: a comparison between wild type and heterozygous reeler mice by immunoelectron microscopy. J. Neurocytol. 30, 413-425 (2001).

6 Shifman, S., Johannesson, M., Bronstein, M., Chen, S. X., Collier, D. A., Craddock, N. J. et al. Genome-wide association identifies a common variant in the reelin gene that increases the risk of schizophrenia only in women. PLoS Genet. 4, e28 (2008).
7 Chen, M. L., Chen, S. Y., Huang, C. H. \& Chen, C. H. Identification of a single nucleotide polymorphism at the $5^{\prime}$ promoter region of human reelin gene and association study with schizophrenia. Mol. Psychiatry 7, 447-448 (2002).

8 Dimitrov, A., Paupe, V., Gueudry, C., Sibarita, J. B., Raposo, G., Vielemeyer, O. et al. The gene responsible for Dyggve-Melchior-Clausen syndrome encodes a novel peripheral membrane protein dynamically associated with the Golgi apparatus. Hum. Mol. Genet. 18, 440-453 (2009).

9 Osipovich, A. B., Jennings, J. L., Lin, Q., Link, A. J. \& Ruley, H. E. Dyggve-MelchiorClausen syndrome: chondrodysplasia resulting from defects in intracellular vesicle traffic. Proc. Natl Acad. Sci. USA 105, 16171-16176 (2008).

10 Escamilla, M. A., McInnes, L. A., Service, S. K., Spesny, M., Reus, V. I., Molina, J. et al. Genome screening for linkage disequilibrium in a Costa Rican sample of patients with bipolar-I disorder: a follow-up study on chromosome 18. Am. J. Med. Genet. 105, 207-213 (2001).

11 Walss-Bass, C., Escamilla, M. A., Raventos, H., Montero, A. P., Armas, R., Dassori, A. et al. Evidence of genetic overlap of schizophrenia and bipolar disorder: linkage disequilibrium analysis of chromosome 18 in the Costa Rican population. Am. J. Med. Genet. B Neuropsychiatr. Genet. 139B, 54-60 (2005).

12 Wellcome Trust Case Control Consortium. Genome-wide association study of 14000 cases of seven common diseases and 3000 shared controls. Nature 447, 661-678 (2007).

13 Cohn, D. H., Ehtesham, N., Krakow, D., Unger, S., Shanske, A., Reinker, K. et al. Mental retardation and abnormal skeletal development (Dyggve-Melchior-Clausen dysplasia) due to mutations in a novel, evolutionarily conserved gene. Am. J. Hum. Genet. 72, 419-428 (2003).

14 Ehtesham, N., Cantor, R. M., King, L. M., Reinker, K., Powell, B. R., Shanske, A. et al. Evidence that Smith-McCort dysplasia and Dyggve-Melchior-Clausen dysplasia are allelic disorders that result from mutations in a gene on chromosome 18q12. Am. J. Hum. Genet. 71, 947-951 (2002).

15 El Ghouzzi, V., Dagoneau, N., Kinning, E., Thauvin-Robinet, C., Chemaitilly, W., ProstSquarcioni, C. et al. Mutations in a novel gene Dymeclin (FLJ20071) are responsible for Dyggve-Melchior-Clausen syndrome. Hum. Mol. Genet. 12, 357-364 (2003).

16 Santos, H. G., Fernandes, H. C., Nunes, J. L. \& Almeida, M. R. Portuguese case of Smith-McCort syndrome caused by a new mutation in the Dymeclin (FLJ20071) gene. Clin. Dysmorphol. 18, 41-44 (2009).

17 Paupe, V., Gilbert, T., Le Merrer, M., Munnich, A., Cormier-Daire, V. \& El Ghouzzi, V. Recent advances in Dyggve-Melchior-Clausen syndrome. Mol. Genet. Metab. 83, 51-59 (2004). 